www.jmscr.igmpublication.org

Impact Factor 5.84

Index Copernicus Value: 83.27

ISSN (e)-2347-176x ISSN (p) 2455-0450

crossref DOI: _https://dx.doi.org/10.18535/jmscr/v5i3.72

Journal Of Medical Science And Clinical Research

IGM Publication

An official Publication of IGM Publication

\title{
The Study of Non-HDL Cholesterol Levels Compared to LDL Cholesterol Levels in Diabetics
}

\author{
Authors \\ Chaitanya Krishna N, Vipan Kumar Goyal, Amit Baweja, Jyoti Chakraverty, \\ Tejesh Krishna Ch, Shobhit Shah \\ Department of medicine, Mata Chanan Devi Hospital, Janakpuri, New Delhi
}

\begin{abstract}
Dyslipidemia is an established risk factor for CAD in patients with type II DM, as well as in nondiabetic patients, and is likely to play a leading role in the increased CVD risk associated with diabetes. If we diagnose and treat dyslipidemia in early stage, we can decrease the risk of atherosclerotic diseases. The dyslipidemia associated with type II DM is typically more complex than simple elevation of systemic low-density lipoprotein cholesterol (LDL-C) levels. Unlike LDL cholesterol, which can be incorrectly calculated in the presence of postprandial hypertriglyceridemia, NON-HDL cholesterol $(N o n-H D L=L D L+V L D L+I D L+$ Lipoprotein $(a))$ is reliable when measured in the non fasting state. As NON-HDL cholesterol measures the Apo B-containing lipoproteins, it can serve as an additional tool to assess cardiovascular risk in people whose risk is not accurately identified by LDL cholesterol alone. This is especially important in patients with diabetes, in whom LDL levels may not be significantly elevated. So a prospective study was carried out in 105 diabetic patients in 20 years and above age group including both sexes irrespective of community or background who were present in inpatient department of medicine, Mata Chanan Devi hospital, New Delhi, during the time period of 2014-2016. It is a 210 bedded, tertiary care hospital in west Delhi, where the patients travel from all North India. Patients with hypothyroidism, renal failure, pregnancy, hypertension, smokers and who are on lipid lowering agent were not included in the study. After taking written informed consent fasting blood sample collected from each research participant for the analysis of lipid profile. Non-HDL-C calculated as TC minus $H D L-C$. LDL-C calculated by direct measurement (enzymatic colour test for the quantitative determination of LDL-Cholesterol in human serum and plasma on Beckman Coulter AU analysers). National Cholesterol Education Programme Adult Treatment Panel III (NCEP-ATPIII) guidelines were referred to define dyslipidemia. The association between LDL and NON-HDL values were evaluated using the Pearson's Chi-Squaretest. P-value $<0.05$ was considered statistically significant .SPSS version 20.0 was used for statistical analysis.

Salient findings Out of 105 patients, there were 56 females and 49 males subjects. Minimum age is 39 years and maximum age is 81 years. Mean age in males is $56.12 \pm 8.05$ and in females 57.91 \pm 7.13.Mean fasting blood sugar was $184.92 \mathrm{mg} / \mathrm{dl}$ and mean post prandial blood sugar was $259.58 \mathrm{mg} / \mathrm{dl}$ as patients were on treatment for diabetes. Average duration of diabetes in present study group was 5.45 years. Mean value of triglycerides, LDL, VLDL, NON HDL, HDL were 201.99, 89.58, 41.19,127.12,38.5mg/dl respectively. As per National Cholesterol Education Programme Adult Treatment Panel III (NCEP-ATPIII) guidelines for LDL the cut off value is $100 \mathrm{mg} / \mathrm{dl}$, for NON HDL the cut off value is $130 \mathrm{mg} / \mathrm{dl}$ and the cut off value for difference between NON HDL and LDL is 30mg/dl in diabetics.

In this study patients who had LDL level <100mg/dl (18\%) had NON HDL level >130mg/dl(28.5\%) in patients with TG $>200$ (46.6\%) Thus in patients with TG >200mg/dl most of the patients had LDL<100mg/dl but had NON HDL $>130 \mathrm{mg} / \mathrm{dl}$ with a significant $\mathrm{p}$ value 0.012 .

Our study showed that the number of patients having NON HDL and LDL difference of $<30 \mathrm{mg} / \mathrm{dl}$ are 39(33\%)and number of patients having NON HDL and LDL difference of >30mg/dl are 66(67\%) with a significant P value of
\end{abstract}


0.019.That means $67 \%$ of present study patients did not had the target of $<30 \mathrm{mg} /$ dl difference between NON HDL and $L D L$.

Conclusion: In our study most of the patients did not had the target of $<30 \mathrm{mg} /$ dl difference between NON HDL and LDL. In patients with $T G>200 \mathrm{mg} / \mathrm{dl}$ most of the patients had $L D L<100 \mathrm{mg} / \mathrm{dl}$ but had NON HDL $>130 \mathrm{mg} / \mathrm{dl}$. The above point clearly says that in diabetic patients with TG $>200 \mathrm{mg} / \mathrm{dl}$ most of the patients had the target LDL level $<100 \mathrm{mg} / \mathrm{dl}$ but not had the target NON HDL level $<130 \mathrm{mg} /$ dl. Characteristic diabetic dyslipidemia pattern i.e increased TG and NON HDL but underestimated LDL is seen in most of the patients in present study. Thus we conclude that in diabetic patients when $T G>200 \mathrm{mg} / \mathrm{dl}$, NON HDL is a better target than LDL in deciding treatment for dyslipidemia.

Recommendations: NON HDL is recommended as a target other than LDL for dyslipidemia in diabetics.

In diabetic patients when $T G>200 \mathrm{mg} / \mathrm{dl}$, NON HDL is a better target than LDL in deciding treatment for dyslipidemia.NON HDL is better marker than LDL for starting treatment of dyslipidemia in diabetic patients to decrease cardiovascular risk. Diabetic patients who reach the target LDL level should be seen for NON HDL level in deciding treatment for dyslipidemia. Elevated levels of NON-HDL are treatable by increasing the intensity of currently available lipid lowering agents, as well as lifestyle modification. All of the currently available lipid-lowering agents (statins, fibrates, niacin, fish-oil products, and intestinally active agents) decrease non-HDL-C levels.

As we have just compared the levels of NON HDL and LDL but not assessed the cardiovascular risk and the study population is also small we suggest further more studies in making NON HDL as a better target than LDL in diabetic patients

\section{Introduction}

Patients with diabetes mellitus have a markedly increased risk for macro vascular disease. A person with diabetes and no known cardiovascular disease (CVD) has the same risk as a person without diabetes who has already had a cardiovascular event. ${ }^{1}$

Atherosclerosis is a multifaceted process involving interactions among immune, coagulation, hormonal, and vascular systems, and dyslipidemia is leading risk factor for atherosclerotic plaque formation and development of coronary heart disease (CHD) events. ${ }^{2}$ Researchers concluded that most of the debilitating complication of diabetes can be prevented or delayed by prospective treatment of hyperglycemia and cardiovascular risk factors. 3,4

Diabetic patients have characteristic pattern of dyslipidemia with decreased level of high density lipoprotein cholesterol (HDL-C) and elevated triglycerides (TG) level. . In diabetes, blood glucose is not utilized by tissues resulting in hyperglycemia. Consequently fatty acids are mobilized from adipose tissue to meet the energy demands and in the process excess fatty acid accumulates in the liver leading to increased triglyceride and VLDL production.

It has been suggested that Non HDL cholesterol which consists of LDL, VLDL, IDL and Lipoprotein (a) might be a useful marker and better predictor of CVD than LDL cholesterol in diabetic as well as non-diabetic individuals. ${ }^{5}$ In diabetes, low density lipoprotein cholesterol (LDL-C) which is used as one of the markers for the risk of CVD, is underestimated, as the elevated triglycerides leads to underestimation of LDL-C according to Friedewald formula

LDL-C $=($ Total Cholesterol $)-($ HDL-C $)-$ (Triglycerides) $/ 5$.

So in such cases the levels of non-HDL-C can be a stronger predictor of CVD as it strongly correlates with atherogenic lipoproteins.

Diabetics have significantly elevated ratio of total cholesterol to high density lipoprotein cholesterol (TC/HDL-C). So there is significant increase in levels of non-HDL-C which is used as marker of dyslipidemia and can also be used to predict the risk of cardiovascular disease in type 2 Diabetes Mellitus.

\section{Objective}

Our aim is to study the levels of NON HDL cholesterol in additional to LDL cholesterol in type 2 diabetes patients and to compare levels of NON HDL cholesterol to LDL cholesterol levels for making decision regarding treatment of dyslipidemia in type 2 diabetics. 


\section{Materials and Method}

A prospective study was carried out in 105 diabetic patients in 20 years and above age group including both sexes irrespective of community or background who were present in inpatient department of medicine, Mata Chanan Devi hospital, New Delhi, during the time period of 2014-2016. It is a 210 bedded, tertiary care hospital in west Delhi. Patients with hypothyroidism, renal failure, pregnancy, hypertension, smokers and who are on lipid lowering agent were not included in the study. Diabetes is a self reported disease. The diagnosis of diabetes is based on American diabetic association criteria. Before starting the study, permission was taken from institutional ethical committee. After taking written informed consent fasting blood sample collected from each research participant for the analysis of lipid profile. Other baseline investigations like haematological profile, blood urea, serum creatinine, serum aminotransferase, serum uric acid, serum electrolytes was also carried out at the time of admission. LDL was measured by direct method. Blood sugar was analysed using hexokinase method. All the data and various findings including the past history, present diagnosis, blood sugar, HbA1c, fasting lipid profile of all subjects were tabulated and evaluated using Microsoft Excel. Non-HDL-C calculated as TC minus HDL-C. LDL-C calculated by direct measurement (enzymatic colour test for the quantitative determination of LDL- Cholesterol in human serum and plasma on Beckman Coulter AU analysers). National Cholesterol Education Programme Adult Treatment Panel III (NCEP-ATPIII) guidelines were referred to define dyslipidemia

The quantitative variables are expressed as mean+/- sd and compared across using unpaired ttest test. The qualitative variables were expressed as frequencies and percentages and compared across two groups using Chi-square test. The association between LDL and NON-HDL values were evaluated using the Pearson's Chi-Square test. A P-value $<0.05$ will be considered statistically significant .SPSS version 20.0 was used for statistical analysis.

\section{Result}

Out of 105 patients, there were 56 females and 49 males subjects. Minimum age is 39 years and maximum age is 81 years. Mean age in males is $56.12 \pm 8.05$ and in females 57.91 \pm 7.13. Mean fasting blood sugar was $184.92 \mathrm{mg} / \mathrm{dl}$ and mean post prandial blood sugar was $259.58 \mathrm{mg} / \mathrm{dl}$ as patients were on treatment for diabetes. Average duration of diabetes in present study group was 5.45 years. Mean value of triglycerides, LDL, VLDL, NON HDL, HDL were 201.99, 89.58, $41.19,127.12,38.5 \mathrm{mg} / \mathrm{dl}$ respectively. Difference between the mean of Non Hdl and LDL is 37 i.e. $>30 \mathrm{mg} / \mathrm{dl}$.

The number of patients having NON HDL and LDL difference of $<30 \mathrm{mg} / \mathrm{dl}$ are $39(33 \%)$ and number of patients having NON HDL and LDL difference of $>30 \mathrm{mg} / \mathrm{dl}$ are $66(67 \%)$ with a significant $\mathrm{P}$ value of 0.019 . That means $67 \%$ of present study patients did not had the target of $<30 \mathrm{mg} / \mathrm{dl}$ difference between NON HDL and LDL.

Total number of patients with LDL $<100 \mathrm{mg} / \mathrm{dl}$ are $74(70.47 \%)$ and NON HDL $>130 \mathrm{mg} / \mathrm{dl}$ are $49(46.6 \%)$. The number of patients whohad LDL level as per ATP III guidelines i.e $<100 \mathrm{mg} / \mathrm{dl}$ are $74(70.47 \%)$, NON HDL $<130 \mathrm{mg} / \mathrm{dl}$ are 51 $(48.5 \%)$ and the number of patients who had LDL <100mg/dl but had NON HDL >130mg/dl are $23(21.9 \%$ ) which is significant with a $p$ value $<0.001$ making it statistically significant.

Total number of patients with TG>200mg/dl are $52(49.5 \%)$ in that $22(20.9 \%)$ patients have NON HDL $<130 \mathrm{mg} / \mathrm{dl}$. Total number of patients with $\mathrm{TG}>200 \mathrm{mg} / \mathrm{dl}$ are $52(49.5 \%)$ in that $30(28.5 \%)$ patients have NON HDL $>130 \mathrm{mg} / \mathrm{dl}$ with a significant $\mathrm{p}$ value 0.025 .

In this study patients who had TG >200 (46.6\%) , $18 \%$ had LDL level $<100 \mathrm{mg} / \mathrm{dl}$ and $28.5 \%$ had NON HDL level $>130 \mathrm{mg} / \mathrm{dl}$. Thus in patients with TG $>200 \mathrm{mg} / \mathrm{dl}$ most of the patients had 


\section{JMSCR Vol||05||Issue||03||Page 18716-18723||March}

LDL $<100 \mathrm{mg} / \mathrm{dl}$ but had Non HDL >130mg/dl with a significant $p$ value 0.012 .

Table 1: Sex distribution

\begin{tabular}{|l|c|}
\hline Male & 49 \\
\hline Female & 56 \\
\hline Total & 105 \\
\hline
\end{tabular}

Table 2: Age distribution in frequency and percentage

\begin{tabular}{|l|c|c|}
\hline AGE IN YEARS & Frequency & Percent \\
\hline$<=40$ & 4 & 3.8 \\
\hline $41-50$ & 10 & 9.5 \\
\hline $51-60$ & 34 & 32.4 \\
\hline $61-70$ & 47 & 44.8 \\
\hline$>70$ & 10 & 9.5 \\
\hline Total & 105 & 100 \\
\hline
\end{tabular}

Table 3: Mean of Fasting, Post Prandial Blood

Sugar, HbA1c, Duration of Diabetes

\begin{tabular}{|l|c|}
\hline & MEAN \pm S.D \\
\hline FASTING & $184.92 \pm 67.17$ \\
\hline POST PRANDIAL & $259.58 \pm 85.31$ \\
\hline HBA1c & $8.31 \pm 2.14$ \\
\hline DURATION OF DIABETES in years & $5.45 \pm 4.01$ \\
\hline
\end{tabular}

Table 4: Mean Values of Cholesterol, Triglycerides, HDL, LDL, VLDL, Non- HDL

\begin{tabular}{|l|c|}
\hline & MEAN \pm SD \\
\hline CHOL & $166.91 \pm 35.53$ \\
\hline TG & $201.99 \pm 63.9$ \\
\hline HDL & $38.75 \pm 12.42$ \\
\hline LDL & $89.58 \pm 25.9$ \\
\hline VLDL & $41.19 \pm 14.5$ \\
\hline NON HDL & $127.12 \pm 26.14$ \\
\hline
\end{tabular}

Table 5: Showing the difference between Non- HDL and LDL with $p$ value

\begin{tabular}{|l|c|c|c|c|c|}
\hline Difference NON HDL - LDL & N & Mean & Std. Deviation & t-value & p-value \\
\hline$<=30$ & 39 & 60.56 & 9.79 & 2.386 & 0.019 \\
\hline$>30$ & 66 & 56.35 & 8.08 & & \\
\hline
\end{tabular}

Table 6A : Non-HDL And LDL Distribution (in total 105 patients with P value)

\begin{tabular}{|c|c|c|c|c|c|c|}
\hline & & \multicolumn{2}{|c|}{ LDL } & \multirow[b]{2}{*}{ Total } & \multirow{2}{*}{$\begin{array}{c}\text { Pearson Chi- } \\
\text { Square }\end{array}$} & \multirow[b]{2}{*}{ p-value } \\
\hline & & $<=100$ & $>100$ & & & \\
\hline \multirow[t]{2}{*}{ NON HDL } & $<=130$ & 51 & 5 & 56 & \multirow{3}{*}{24.46} & \multirow{3}{*}{$<0.001$} \\
\hline & $>130$ & 23 & 26 & 49 & & \\
\hline Total & & 74 & 31 & 105 & & \\
\hline
\end{tabular}

Table 6 B: Non-HDL and LDL Frequency Distribution (in percentage of total 105 patients.)

\begin{tabular}{|c|c|c|}
\hline & Frequency & Percent \\
\hline LDL $<100 \& N H D L<130$ & 51 & 48.5 \\
\hline LDL $<100 \& N H D L>130$ & 23 & 21.9 \\
\hline LDL $>100 \& N H D L>130$ & 26 & 24.7 \\
\hline LDL $>100 \& N H D L<130$ & 5 & 4.7 \\
\hline Total & 105 & 100 \\
\hline
\end{tabular}

Table 7A: No-HDL and Triglyceride Distribution (in total 105 patients with $\mathrm{P}$ value.)

\begin{tabular}{|c|c|c|c|c|c|c|}
\hline & & NON HDL & & Total & \multirow{2}{*}{$\begin{array}{c}\text { Pearson Chi- } \\
\text { Square }\end{array}$} & \multirow[b]{2}{*}{$\mathrm{p}$-value } \\
\hline & & $<=130$ & $>130$ & & & \\
\hline TG & $<=200$ & 34 & 19 & 53 & \multirow{3}{*}{5.03} & \multirow{3}{*}{0.025} \\
\hline & $>200$ & 22 & 30 & 52 & & \\
\hline Total & & 56 & 49 & 105 & & \\
\hline
\end{tabular}

Table 7B: Non-HDL and Triglyceride Frequency Distribution (in percentage of total 105 patients.)

\begin{tabular}{|l|c|c|}
\hline TG group & Frequency & Percent \\
\hline TG $>200 \&$ NHDL $>130$ & 30 & 28.5 \\
\hline TG $>200$ \& NHDL $<130$ & 22 & 20.9 \\
\hline TG $<200 \&$ NHDL $<130$ & 34 & 32.3 \\
\hline TG $<200 \&$ NHDL $>130$ & 19 & 18.0 \\
\hline Total & 105 & 100 \\
\hline
\end{tabular}


Table 8: LDL and Triglyceride Distribution in total 105 patients divided into two groups Non-HDL $<130$ and $>130$ with $P$ value

\begin{tabular}{|c|c|c|c|c|c|c|}
\hline NON HDL & TRIGLYCERIDE & LDL & & & Pearson & p- \\
\hline & & $<100$ & $>100$ & Total & Chi-Square & value \\
\hline$<130$ & $<=200$ & 31 & 3 & 34 & \multirow{3}{*}{0.354} & \multirow{3}{*}{0.838} \\
\hline & $200-300$ & 17 & 2 & 19 & & \\
\hline & $300-400$ & 3 & 0 & 3 & & \\
\hline$>130$ & $<=200$ & 4 & 15 & 19 & \multirow{5}{*}{11.03} & \multirow{5}{*}{0.012} \\
\hline & '200 - 300 & 12 & 8 & 20 & & \\
\hline & $300-400$ & 3 & 3 & 6 & & \\
\hline & $>400$ & 4 & 0 & 4 & & \\
\hline & Total & 23 & 26 & 49 & & \\
\hline
\end{tabular}

\section{Discussion}

The National Cholesterol Education Program Adult Treatment Panel III (ATP III) defined diabetes as a CHD risk equivalent with an LDL treatment goal of $<100 \mathrm{mg} / \mathrm{dl}^{6}{ }^{6}$ Although patients are divided into risk categories according to their levels of LDL, HDL cholesterol, and triglycerides, both the ADA and the ATP III guidelines emphasized that LDL lowering remains the top priority for lipid lowering, and non-HDL is the secondary goal of treatment when the triglyceride level is $>200 \mathrm{mg} / \mathrm{dl}$. Thus in this study focus has been done on LDL, NON HDL and Triglycerides to know the dyslipidemia pattern in type 2 diabetes patients.

The recommended NON-HDL cholesterol goal is $30 \mathrm{mg} / \mathrm{dl}$ above the LDL goal. ${ }^{7,8,9}$ The rationale for the $30 \mathrm{mg} / \mathrm{dL}$ gap between LDL-C and nonHDL-C goals is as follows:

(1) Non-HDL-C constitutes LDL-C, VLDL-C, IDL-C Lp(a).

(2) VLDL-C, the principal atherogenic lipoprotein after LDL-C, is calculated as triglycerides/5.

(3) the upper limit of optimal triglycerides is less than $150 \mathrm{mg} / \mathrm{dL}$ and thus the optimal level of VLDL-C is less than $30 \mathrm{mg} / \mathrm{dl}$ (or $150 / 5 \mathrm{mg} / \mathrm{dL}$ ). Thus, under conditions of optimally managed triglycerides, the non-HDL-C goal is set $30 \mathrm{mg} / \mathrm{dl}$ higher than the optimal LDL-C goal.

The present study was conducted to assess the significance of NON HDL over LDL in type 2 diabetics with triglycerides $>200 \mathrm{mg} / \mathrm{dl}$ and to decide whether to treat diabetics based on NON HDL value.Our study shows the number of patients having NON HDL and LDL difference of $<30 \mathrm{mg} / \mathrm{dl}$ are $39(33 \%)$ and number of patients having NON HDL and LDL difference of $>30 \mathrm{mg} / \mathrm{dl}$ are $66(67 \%)$ with a significant $\mathrm{P}$ value of 0.019 .Thus most of the present study patients didn't met the criteria of having NON HDL and LDL difference of $<30 \mathrm{mg} / \mathrm{dl}$. These results are in accordance to the studies conducted byCui et al, ${ }^{10}$ Koji Sugimoto et al. ${ }^{11}$

Most of the studies done are about comparing Non HDL over LDL in assessing the cardiovascular risk in diabetics. In a post hoc analysis of patients with diabetes from four prospective cohort studies - the Framingham Cohort Study, the Framingham Offspring Study, the Lipid Research Clinics Prevalence Follow-Up Study, and the usual-care group of the Multiple Risk Factor Intervention Trial - the relative risk of death for diabetic (compared with nondiabetic) patients was 7.2 for those with elevated non-HDL cholesterol( $>130 \mathrm{mg} / \mathrm{dl}$ ) and low LDL $(<100 \mathrm{mg} / \mathrm{dl}){ }^{12}$

In our study cardiovascular assessment has not done but based on previous studies ${ }^{12} \mathrm{NON}$ HDL and LDL were compared to decide whether to treat the diabetics based on NON HDL value. In this study patients who had LDL levels as per ATP III guidelines i.e $<100 \mathrm{mg} / \mathrm{dl}$ are $74(70 \%)$ but had NON HDL levels <130mg/dl are 23(21\%) which is significant with a $\mathrm{p}$ value $<0.001$. Thus in this study patients who had LDL in normal range most of them had NON HDL above the target level .These patients are at risk of developing cardiovascular diseases if we treat diabetics only based on LDL, so lipid lowering therapy has to be 
started in these patients based on NON HDL. These results are in accordance to the studies conducted by N. Ram \& J. Abdul etal ${ }^{13}$ Raul D. Santos et $\mathrm{al}^{14}$.

In this study patients with $\mathrm{TG}>200 \mathrm{mg} / \mathrm{dl}$ are $52(49.5 \%)$ in that $30(28.5 \%)$ patients have NON HDL $>130 \mathrm{mg} / \mathrm{dl}$.This result signifies that in most of the patients with $\mathrm{TG}>200 \mathrm{mg} / \mathrm{dl}$ had not met the NON HDL target $<130 \mathrm{mg} / \mathrm{dl}$. These results are in accordance to the studies conducted by Raul D. Santos et $\mathrm{al}^{14}$, M.Saiedullah et $\mathrm{al}^{15}$, Davidson et $\mathrm{al}^{16}$.

In this study patients with $\mathrm{TG}>200 \mathrm{mg} / \mathrm{dl}$ are $49(46.6 \%)$ in that the patients who had LDL $<100 \mathrm{mg} / \mathrm{dl}$ are $19(18 \%)$ and NON HDL $>130 \mathrm{mg} / \mathrm{dl}$ in $30(28.5 \%)$ patients.It means patients who had LDL levels $<100 \mathrm{mg} / \mathrm{dl}(18 \%)$ did not had NON HDL target $<130 \mathrm{mg} / \mathrm{dl}(28.5 \%)$ in patients with TG $>200 \mathrm{mg} / \mathrm{dl}(46.6 \%)$ Thus in patients with $\mathrm{TG}>200 \mathrm{mg} / \mathrm{dl}$ most of the patients had LDL $<100 \mathrm{mg} / \mathrm{dl}$ but had NON HDL $>130$ $\mathrm{mg} / \mathrm{dl}$ with a significant $\mathrm{p}$ value 0.012 . This result is in accordance to the studies conducted by Davidson et al, ${ }^{16}$ Liu et al, ${ }^{17}$ Mark L et al ${ }^{18}$.

The above findings suggest that type 2 diabetic patients have more triglyceride levels so that LDL level is underestimated but the NON HDL ( total cholesterol minus HDL) levels are raised. As LDL which is the primary target in treatment of dyslipidemia is underestimated in diabetic patients an alternative NON HDL can be used as target in treating dyslipidemia in diabetics. This point was supported by a recent analysis of data combined from 68 studies, ${ }^{19}$

NON-HDL-C was the best predictor among all cholesterol measures, both for CAD events and for strokes.

Our study showed that diabetic patients who had TG levels >200mg/dl most of them had LDL $<100 \mathrm{mg} / \mathrm{dl}$ and the same patients had NON HDL $>130 \mathrm{mg} / \mathrm{dl}$. This finding signifies that these patients are to be treated based on NON HDL value though the LDL value is normal to decrease the cardiovascular risk.

\section{Conclusion}

In our study most of the patients did not had the target of $<30 \mathrm{mg} / \mathrm{dl}$ difference between NON HDL and LDL. In patients with TG $>200 \mathrm{mg} / \mathrm{dl}$ most of the patients had $\mathrm{LDL}<100 \mathrm{mg} / \mathrm{dl}$ but had NON HDL $>130 \mathrm{mg} / \mathrm{dl}$. The above point clearly says that in diabetic patients with TG $>200 \mathrm{mg} / \mathrm{dl}$ most of the patients had the target LDL level $<100 \mathrm{mg} / \mathrm{dl}$ but not had the target NON HDL level $<130 \mathrm{mg} / \mathrm{dl}$. Characteristic diabetic dyslipidemia pattern i.e increased TG and NON HDL but underestimated LDL is seen in most of the patients in present study. Thus we conclude that in diabetic patients when TG $>200 \mathrm{mg} / \mathrm{dl}$, NON HDL is a better target than LDL in deciding treatment for dyslipidemia.

\section{Recommendations}

- NON HDL is recommended as a target other than LDL for dyslipidemia in diabetics.

- In diabetic patients when TG $>200 \mathrm{mg} / \mathrm{dl}$, NON HDL is a better target than LDL in deciding treatment for dyslipidemia.

- NON HDL is better marker than LDL for starting treatment of dyslipidemia in diabetic patients to decrease cardiovascular risk.

- Diabetic patients who reach the target LDL level should be seen for NON HDL level in deciding treatment for dyslipidemia.

- Elevated levels of NON-HDL are treatable by increasing the intensity of currently available lipid lowering agents, as well as lifestyle modification. All of the currently available lipid-lowering agents (statins, fibrates, niacin, fish-oil products, and intestinally active agents) decrease nonHDL-C levels.

- As we have just compared the levels of NON HDL and LDL but not assessed the cardiovascular risk and the study population is also small we suggest further 
more studies in making NON HDL as a better target than LDL in diabetic patients.

\section{References}

1. Harmel AP. National diabetes data group, report of the expert committee on diagnosis and classification of diabetes methods. Diabetes case 2002; 23: S4-S19.

2. Wong ND, Pio JR, Frankilin SS, L'Italien GJ, Kamath TV, Williams JR. Preventing coronary events by optimal control of blood pressure and lipids in patients with metabolic syndrome. Am J Cardiol 2003; 91: 1421-26.

3. Collins R, Peto R, Armtage J. The MRC/BHF Heart protection study: preliminary results. Int J CliPrac 2002; 56:S83-86.

4. Colwell JA. American Diabetic Association. Aspirin therapy in diabetes. Diabetes care 2003; 26: S87-88.

5. Cui Y, Bluementhal RS, Flaws JA, Whioteman MK, Langenberg P, Bbush TL et al. Non high density lipoprotein cholesterol level as a predictor of cardiovascular disease mortality. Arch Inter Med 2001; 161: 1413-19.

6. Expert Panel on Detection, Evaluation, and Treatment of High Blood Cholesterol in Adults: Executive Summary of the Third Report of the National Cholesterol Education Program (NCEP) Expert Panel on Detection, Evaluation, and Treatment of High Blood Cholesterol in Adults (Adult Treatment Panel III).JAMA2001; 285: 2486-2497.

7. Sniderman AD, Scantlebury T, Cianflone $\mathrm{K}$ : Hypertriglyceridemic hyperapoB: the unappreciated atherogenic dyslipoproteinemia in type 2 diabetes mellitus. Ann Intern Med 2001; 135:447-459

8. J. I. Cleeman, "Executive summary of the third report of the National Cholesterol Education Program (NCEP) expert panel on detection, evaluation, and treatment of high blood cholesterol in adults (adult treatment panel III)," Journal of the American Medical Associatio2001;285( 19): 2486-2497.

9. R. McPherson, J. Frohlich, G. Fodor, and J. Genest, "Canadian Cardiovascular Society position statement-recommenddations for the diagnosis and treatment of dyslipidemia and prevention of cardiovascular disease," Canadian Journal of Cardiology 2006; 22(11): 913-927.

10. Cui Y, Blumenthal RS, Flaws JA, Whiteman MK, Langenberg P, et al. Nonhigh-density lipoprotein cholesterol level as a predictor of cardiovascular disease mortality. Arch Intern Med. 2001;161 :1413-1419.

11. Koji Sugimoto, KazumasaIsobe, Yasushi Kawakami, Nobuhiro Yamada. The Relationship Between Non HDL Cholesterol And Other Lipid Parameters In Japanese Subjects. J Atheroscler Thromb 2005;12:107-110.

12. Liu J, Sempos C, Donahue RP, Dorn J, Trevisan M, Grundy SM: Joint distribution of non- HDL and LDL cholesterol and coronary Heart disease risk prediction among individuals with and without diabetes. Diabetes Care 2005; 28:1916-1921.

13. N. Ram \& J. Abdul . Non-HDL and LDL cholesterol in type 2 diabetes mellitus patients at tertiary care hospital of Pakistan. Endocrine Abstracts 2012; 29: 597.

14. Raul D. David D. Waters, Lisa Tarasenko, Michael Messig,J. WouterJukema, et al. A comparison of non-HDL and LDL cholesterol goal attainment in a large, multinational patient population: The Lipid Treatment Assessment Project 2. Atherosclerosis 2012 ;224(1):150-3.

15. M Saiedullah, S Begum, S Hayat, SM Kamaluuddin, Rahman, Mah khan. NonHDL Cholesterol Versus LDL Cholesterol as a CVD Risk Factor in Diabetic 
Subjects. J BanagladeshCollPhysSurg 2013; 31: 199-203.

16. Davidson MH, Maki KC, Pearson TA, et al. Results of the National Cholesterol Education (NCEP) Program Evaluation ProjecT Utilizing Novel E-Technology (NEPTUNE) II survey and implications for treatment under the recent NCEP Writing Group recommendations. Am JCardiol 2005;96:556-63.

17. Liu J, Sempos CT, Donahue RP, et al. Non-high-density lipoprotein and verylow-density lipoprotein cholesterol and their risk predictive values in coronary heart disease. Am J Cardiol2006;98:13638.

18. Mark L, Vallejo-Vaz AJ, Reiber I, Paragh G, KondapallySeshasai SR, Ray KK. NonHDL cholesterol goal attainment and its relationship with triglyceride concentrations among diabeticsubjects with cardiovascular disease: A nationwide survey of 2674 individuals in Hungary. Atherosclerosis 2015;241(1):62-8.

19. Emerging Risk Factors Collaboration, Di Angelantonio E, Sarwar N, Perry P, Kaptoge S, Ray KK, et al. Major lipids, apolipoproteins, and risk of vascular disease. JAMA 2009;302(18):1993-2000.
LIST OF ABBREVIATION USED

\begin{tabular}{|c|c|l|}
\hline $\begin{array}{c}\text { S } \\
\text { no. }\end{array}$ & & \\
\hline 1. & $\%$ & Percentage \\
\hline 2. & $<$ & Less than \\
\hline 3. & $>$ & More than \\
\hline 4. & Apo & Apo lipoprotein \\
\hline 5. & ATP & Adult Treatment Panel \\
\hline 6. & DM & Diabetes Mellitus \\
\hline 7. & FBS & Fasting Blood Sugar \\
\hline 8. & HbAlc & Glycosylated Haemoglobin \\
\hline 9. & HDL c & High Density Lipoprotein Cholesterol \\
\hline 10 & LDL c & Low Density Lipoprotein Cholesterol \\
\hline 11 & NCEP & National Cholesterol Education Program \\
\hline 12 & PPBS & Post Prandial Blood Sugar \\
\hline 13 & TC/CH & Total Cholesterol \\
\hline 14 & TG & Triglycerides \\
\hline 15 & VLDL c & Very Low Density Lipoprotein Cholesterol \\
\hline 16 & CHD & Coronary Heart Disease \\
\hline 17 & R & Nonfasting or Random \\
\hline 18 & F & Fasting \\
\hline
\end{tabular}

